\title{
EVALUASI KESESUAIAN LAHAN UNTUK TANAMAN PALA (Myristica fragrans Houtt.) DI KECAMATAN CIKALONG KULON, SUKARESMI DAN MANDE KABUPATEN CIANJUR
}

\section{LAND SUITABILITY EVALIATION FOR NUTMEG (Myristica fragrans Houtt.) IN CIKALONGKULON, SUKARESMI AND MANDE DISTRICTS CIANJUR REGENCY}

\author{
Yanto Yulianto dan Ahmad Syarif Purnama \\ Jurusan Agroteknologi, Fakultas Pertanian Universitas Siliwangi \\ Jl. Siliwangi No. 24 Kota Tasikmalaya \\ Korespondensi : yantotsk@yahoo.co.id
}

\begin{abstract}
ABSTRAK
Sektor perkebunan termasuk pala di Kabupaten Cianjur banyak dikembangkan di wilayah selatan, padahal Cianjur utara memiliki potensi untuk pengembangan perkebunan termasuk pala, khususnya di Kecamatan Cikalongkulon, Sukaresmi dan Mande. Tujuan dari penelitian ini adalah untuk mengetahui potensi kesesuaian lahan di Kecamatan Cikalongkulon, Sukaresmi dan Mande. Metode Penelitian yang digunakan merupakan metode yang merujuk pada kerangka yang dibuat oleh FAO, meliputi pengumpulan data, survei lapangan serta matching antara karakteristik lahan dengan syarat tumbuh tanaman. Dari hasil penelitian menunjukkan bahwa untuk tanaman pala memiliki kelas S3 (sesuai marginal) di Kecamatan Cikalongkulon, Sukaresmi dan Mande dengan faktor pembatas berupa kemiringan lereng, drainase dan kejenuhan basa.
\end{abstract}

Kata Kunci : Pala dan Evaluasi Kesesuaian Lahan

\section{ABSTRACT}

The plantation sector including nutmeg in Cianjur Regency is widely developed in the southern region, whereas North Cianjur has the potential for plantation development including nutmeg, especially in the Cikalongkulon, Sukaresmi and Mande sub-districts. The purpose of this study was to determine the potential for land suitability in Cikalongkulon, Sukaresmi and Mande sub-districts. The research method used is the framework made by FAO, including data collection, field surveys and matching between the characteristics of the land with the suitability for growing plants. The results showed that nutmeg plants had S3 class (marginally suitable) in Cikalongkulon, Sukaresmi and Mande sub-districts with limiting factors such as slope, drainage and alkaline saturation.

Keywords : Nutmeg and Land Suitability Evaluation

PENDAHULUAN

Kabupaten Cianjur terletak di Provinsi Jawa Barat. Wilayah Kabupaten Cianjur terdiri dari 32 kecamatan dengan luas wilayah 361.434,98 ha. Lahan di Kabupaten Cianjur terdiri atas lahan 
pertanian non sawah seluas $261.616,7$ ha, lahan sawah seluas $66.934,09$ ha dan lahan non pertanian seluas $33.388,4$ ha. Luas lahan perkebunan di Kabupaten Cianjur tercatat seluas 31.549,13 ha (BPS Kabupaten Cianjur, 2018).

Pala (Myristica fragrans Houtt.) merupakan tanaman rempah dan tanaman perkebunan yang memiliki nilai ekonomi yang tinggi. Produksi pala Indonesia sekitar 19,9 ribu ton per tahun (Nurdjannah, 2007). Di Jawa Barat tanaman pala banyak dibudidayakan di wilayah Kabupaten Cianjur, Kabupaten Bogor, dan Kabupaten Sukabumi.

Sektor perkebunan termasuk pala dan kopi di Kabupaten Cianjur banyak dikembangkan di wilayah Cianjur bagian selatan. Padahal, wilayah Cianjur utara memiliki potensi untuk pengembangan perkebunan di Kabupaten Cianjur. Hal ini dikarenakan masih banyaknya lahan yang belum dimanfaatkan secara optimal, terutama di wilayah Kecamatan Cikalongkulon, Sukaresmi dan Mande. Namun, sebelum dilakukan pengembangan wilayah perkebunan di Kecamatan Cikalongkulon, Sukaresmi dan Mande, diperlukan evaluasi kesesuaian lahan untuk mengetahui karakteristik lahan di wilayah tersebut serta untuk mengetahui kesesuaian lahan tersebut untuk pengembangan wilayah perkebunan khususnya untuk tanaman pala. Menurut Arsyad (2010) hasil evaluasi lahan memberikan alternatif penggunaan lahan dan batas-batas kemungkinan penggunaannya serta tindakan-tindakan pengelolaan yang diperlukan agar lahan dapat digunakan secara lestari.

\section{BAHAN DAN METODE}

Alat yang digunakan dalam penelitian ini adalah bor tanah, meteran, plastik, box wadah tanah, Global Positioning System (GPS), soil tester, seperangkat laptop, kamera dan alat tulis. Data yang digunakan dalam penelitian ini berupa peta administrasi Kabupaten Cianjur, peta curah hujan Kabupaten Cianjur, peta tanah semi detail Kabupaten Cianjur dan kriteria kesesuaian lahan untuk tanaman pala.

Pada penelitian ini metode yang digunakan adalah metode survei langsung di lapangan untuk mengidentifikasi karakteristik lahan berdasarkan satuan peta tanah (SPT) yang terbentuk. Satuan peta tanah yang digunakan dalam penelitian ini merupakan hasil pemetaan yang dilakukan oleh Balai Besar Sumberdaya Lahan Pertanian (BBSDLP) tahun 2016.

Selanjutnya dilakukan pencocokan (matching) antara karakteristik lahan dengan kriteria kesesuaian lahan untuk tanaman pala. Kesesuaian lahan dalam penelitian ini merujuk pada kerangka yang dibuat oleh FAO tahun 1976.

\section{HASIL DAN PEMBAHASAN}

\section{Tanah}

Pada wilayah penelitian terdiri dari beberapa jenis tanah yaitu kambisol, podsolik, gleisol, mediteran, andosol dan arenosol. Pada sistem klasifikasi tanah menurut USDA, tanah Kambisol, Gleisol dan Arenosol masuk kedalam ordo Inceptisols. Inceptisols cenderung ditandai dengan pelapukan tanah yang lemah, cukup menandai untuk perkembangan tanah ringan (Palmer, 2005).

Podsolik dalam sistem klasifikasi tanah USDA masuk ke dalam ordo Ultisols. Tanah Ultisol umumnya mempunyai nilai kejenuhan basa $<35 \%$, karena batas ini merupakan salah satu syarat untuk klasifikasi tanah Ultisol menurut Soil Taxonomy. Beberapa jenis tanah Ultisol mempunyai kapasitas tukar kation < 16 $\mathrm{cmol} / \mathrm{kg}$ liat, yaitu Ultisol yang mempunyai horizon kandik (Prasetyo dan Suriadikarta, 2006). 
Tanah Mediteran dalam sistem klasifikasi USDA termasuk ordo Alfisols. Menurut Wijanarko, Sudaryono dan Sutarno (2007), tanah Alfisols umumnya identik dengan warna merah. Warna merah tersebut terbentuk karena tingginya kadar besi dalam tanah yang mengalami oksidasi.
Tanah Andosol dalam sistem klasifikasi USDA termasuk ordo Andisols. Tanah Andisols di Indonesia memiliki kisaran $\mathrm{pH}$ yang cukup besar, yaitu antara 3,4 sampai 6,7 dengan rata-rata 5,4. Tetapi, kisaran 4,5 sampai 5,5 merupakan kisaran $\mathrm{pH}$ paling banyak, sedangkan kedua terbanyak kisaran pH antara 5,5 sampai 6,5 (Juarti, 2006).

\section{Kemiringan Lereng}

Kemiringan lereng disajikan pada Tabel 1.

Tabel 1. Kemiringan Lereng Kecamatan Cikalongkulon, Sukaresmi dan Mande Kabupaten Cianjur

\begin{tabular}{|c|c|c|c|}
\hline SPT & Lokasi & $\begin{array}{c}\text { Kemiringan Lereng } \\
(\%)\end{array}$ & Relief \\
\hline 4 & Kecamatan Cikalongkulon & 1 sampai 3 & Agak Datar \\
\hline 22 & $\begin{array}{l}\text { Kecamatan Cikalongkulon dan } \\
\text { Sukaresmi }\end{array}$ & 25 sampai 40 & Berbukit Curam \\
\hline 27 & Kecamatan Sukaresmi & 8 sampai 15 & Landai \\
\hline 29 & Kecamatan Mande & 3 sampai 8 & Agak Landai \\
\hline 30 & Kecamatan Mande & 1 sampai 3 & Agak Datar \\
\hline 36 & Kecamatan Cikalongkulon dan Mande & 15 sampai 25 & $\begin{array}{l}\text { Berbukit Agak } \\
\text { Curam }\end{array}$ \\
\hline 37 & $\begin{array}{l}\text { Kecamatan Cikalongkulon, Sukaresmi } \\
\text { dan Mande }\end{array}$ & 25 sampai 40 & Berbukit Curam \\
\hline 39 & Kecamatan Sukaresmi & 15 sampai 25 & $\begin{array}{l}\text { Bergunung Agak } \\
\text { Curam }\end{array}$ \\
\hline 41 & $\begin{array}{l}\text { Kecamatan Cikalongkulon, Sukaresmi } \\
\text { dan Mande }\end{array}$ & Lebih dari 40 & $\begin{array}{l}\text { Bergunung Sangat } \\
\text { Curam }\end{array}$ \\
\hline 42 & Kecamatan Cikalongkulon & 25 sampai 40 & Berbukit Curam \\
\hline
\end{tabular}

Kemiringan lereng merupakan salah satu faktor yang harus diperhatikan untuk pengembangan kawasan pertanian karena kemiringan lereng akan berpengaruh terhadap tingkat bahaya erosi dan longsor.

Menurut Yulina et al. (2015), kemiringan lereng juga berpengaruh terhadap tingkat erodibilitas dimana semakin curam kemiringan lereng maka erodibilitas tanah akan semakin tinggi dan menyebabkan semakin tidak tahan terhadap erosi.

\section{Iklim}

Berdasarkan peta curah hujan Kabupaten Cianjur, Kecamatan Mande memiliki curah hujan berkisar antara 2.000 sampai 3.500 milimeter per tahun. Kecamatan Cikalongkulon memiliki curah hujan berkisar antara 2.000 sampai 3.000 milimeter per tahun dan Kecamatan Sukaresmi memiliki curah hujan berkisar antara 3.000 sampai 4.000 milimeter per tahun. Wilayah Cianjur bagian utara memiliki rata-rata kelembaban udara sekitar 80\% (BMKG, 2018). Data temperatur udara disajikan dalam Tabel 2.

Iklim memegang peranan penting dalam penentuan jenis dan kultivar tanaman yang dibudidayakan dan dalam penentuan hasil akhir. Keberhasilan produksi tanaman mensyaratkan penggunaan sumberdaya 
iklim seperti penyinaran matahari, karbon dioksida dan air secara efisien. Fenologi dan laju perkembangan suatu tanaman tergantung pada faktor-faktor iklim seperti suhu, panjang penyinaran matahari dan persediaan air berupa curah hujan (Setiawan, 2009).

Tabel 2. Data Suhu Kecamatan Cikalongkulon, Sukaresmi dan Mande Kabupaten Cianjur

\begin{tabular}{clcc}
\hline SPT & \multicolumn{1}{c}{ Lokasi } & $\begin{array}{c}\text { Ketinggian } \\
\text { Tempat }(\mathrm{mdpl})\end{array}$ & $\begin{array}{c}\text { Suhu Udara } \\
\left({ }^{0} \mathrm{C}\right)\end{array}$ \\
\hline 22 & Kecamatan Cikalongkulon dan Sukaresmi & $220-505$ & $23,27-24,98$ \\
30 & Kecamatan Mande & $243-272$ & $24,67-24,84$ \\
36 & Kecamatan Cikalongkulon dan Mande & $316-461$ & $23,53-24,40$ \\
37 & Kecamatan Cikalongkulon, Sukaresmi dan & $330-877$ & $21,04-24,32$ \\
39 & Mande & $849-1.009$ & $20,25-21,21$ \\
42 & Kecamatan Sukaresmi & $278-362$ & $24,13-24,63$ \\
\hline
\end{tabular}

\section{Sifat Fisik Tanah}

Sifat fisik tanah disajikan dalam Tabel 3. Drainase tanah menunjukkan kecepatan hilangnya air dari tanah, baik meresap maupun sebagai aliran permukaan atau keadaan tanah yang menunjukkan lamanya dan seringnya jenuh air (Hardjowigeno dan Widiatmaka, 2015). Keadaan drainase tanah menunjukkan jenis tanaman yang dapat tumbuh dan cocok ditanam didaerah tersebut. Pada tanaman kopi arabika, kopi robusta dan pala menghendaki tanah yang tidak selalu tergenang air atau memiliki drainase yang baik. Adanya batuan baik di permukaan tanah atau didalam tanah dapat mengganggu perakaran tanaman serta mengurangi kemampuan tanah untuk berbagai penggunaan.

Tabel 3. Sifat Fisik Lahan Kecamatan Cikalongkulon, Sukaresmi dan Mande Kabupaten Cianjur

\begin{tabular}{ccccccc}
\hline SPT & Drainase & $\begin{array}{c}\text { Batuan } \\
\text { Permukaan }\end{array}$ & $\begin{array}{c}\text { Singkapan } \\
\text { Batuan }\end{array}$ & $\begin{array}{c}\text { Bahan } \\
\text { kasar }\end{array}$ & Tekstur & $\begin{array}{c}\text { Kedalaman } \\
\text { Efektif }\end{array}$ \\
\hline 22 & Baik & $<5 \%$ & $<5 \%$ & $5 \%$ & Halus & $>100 \mathrm{~cm}$ \\
30 & Terhambat & $<5 \%$ & $<5 \%$ & $5 \%$ & Halus & $>100 \mathrm{~cm}$ \\
36 & Baik & $<5 \%$ & $<5 \%$ & $5 \%$ & Halus & $>100 \mathrm{~cm}$ \\
37 & Baik & $<5 \%$ & $<5 \%$ & $5 \%$ & Halus & $>100 \mathrm{~cm}$ \\
39 & Baik & $<5 \%$ & $<5 \%$ & $5 \%$ & Halus & $>100 \mathrm{~cm}$ \\
42 & Baik & $<5 \%$ & $<5 \%$ & $5 \%$ & Halus & $>100 \mathrm{~cm}$ \\
\hline
\end{tabular}

Tekstur tanah akan mempengaruhi kapasitas lapang air pada tanah. Hasil penelitian yang dilakukan oleh Haridjaja, Baskoro dan Setianingsih (2013), menunjukkan bahwa kadar air kapasitas lapang pada tekstur tanah liat lebih besar daripada lempung liat berpasir dan lempung berpasir. Hal ini dikarenakan kapasitas menahan air pada tanah bertekstur liat lebih besar daripada lempung liat berpasir dan 
lempung berpasir. Selain itu juga pada tanah dengan tekstur liat memiliki kandungan $\mathrm{N}$ total, K-tersedia dan $\mathrm{C}$ organik lebih tinggi jika dibandingkan dengan lempung liat berpasir dan lempung berpasir. Menurut Arsyad (2010), kedalaman efektif adalah kedalaman tanah yang baik bagi pertumbuhan akar tanaman, yaitu kedalaman sampai pada lapisan yang tidak dapat ditembus oleh akar tanaman.

\section{Sifat Kimia Tanah}

Pada lokasi penelitian, diketahui bahwa pH tanah pada semua SPT bersifat masam. pH tanah merupakan sifat kimia tanah yang terpenting karena menentukan berbagai sifat tanah lainnya seperti ketersediaan unsur hara, keberadaan mikroorganisme yang paling dominan dalam tanah dan kecepatan proses perombakan bahan organik dalam tanah (Supriyadi, 2007).

Kandungan Nitrogen pada lokasi penelitian berada pada kriteria sedang di semua SPT yang diamati, kandungan fosfor berada pada kriteria sedang di SPT 22, SPT 36, SPT 37, SPT 39 dan SPT 42 sedangkan pada SPT 30 berada pada kriteria sangat rendah dan kandungan kalium berada pada kriteria rendah di SPT 30, SPT 36, SPT 37 dan SPT 39 sedangkan pada SPT 22 dan
SPT 42 berada pada kriteria sedang. Untuk kandungan C-organik berada pada kriteria rendah di SPT 30 dan sedang pada SPT 22, SPT 36, SPT 37, SPT 39 dan SPT 42.

Pada SPT 30, SPT 36, SPT 37 dan SPT 39 memiliki Kapasitas Tukar Kation (KTK) yang sedang sedangkan pada SPT 22 dan 42 memiliki KTK yang tinggi. KTK tanah mencerminkan kemampuan koloid tanah dalam menjerap dan mempertukarkan kation-kationnya dalam tanah. Makin tinggi KTK dalam tanah makin tinggi pula kemampuan tanah dalam menjerap dan mempertukarkan hara dalam tanah (Susila, 2013).

Pada SPT 37 dan SPT 39 memiliki Kejenuhan Basa (KB) dengan kriteria rendah, pada SPT 22, SPT 30 dan SPT 36 memiliki KB dengan kriteria sedang dan pada SPT 42 memiliki KB dengan kriteria tinggi. Kejenuhan Basa (KB) merupakan perbandingan antara semua kation basa dengan KTK tanah (Susila, 2013).

\section{Kesesuaian Lahan Aktual}

Kesesuaian lahan aktual untuk tanaman pala disajikan dalam tabel 4. Untuk tanaman kopi arabika disajikan dalam tabel 5 dan untuk kopi robusta disajikan dalam tabel 6.

Tabel 4. Kelas Kesesuaian Lahan Aktual untuk Tanaman Pala di Kecamatan Cikalongkulon, Sukaresmi dan Mande Kabupaten Cianjur

\begin{tabular}{clcc}
\hline SPT & \multicolumn{1}{c}{ Lokasi } & $\begin{array}{c}\text { Kelas } \\
\text { Kesesuaian } \\
\text { Lahan Aktual }\end{array}$ & Faktor Pembatas \\
\hline 22 & Kecamatan Cikalongkulon dan Sukaresmi & S3e & Kemiringan Lereng \\
30 & Kecamatan Mande & S3r & Drainase \\
36 & Kecamatan Cikalongkulon dan Mande & S3e & Kemiringan Lereng \\
37 & Kecamatan Cikalongkulon, Sukaresmi dan & S3fe & Kejenuhan Basa dan \\
& Mande & Kemiringan lereng \\
39 & Kecamatan Sukaresmi & Kejenuhan Basa dan \\
42 & Kecamatan Cikalongkulon & Kemiringan lereng \\
\hline \multicolumn{2}{l}{ Keterangan : S3 (Sesuai Marginal), N (Tidak Sesuai), e (Bahaya Erosi), r (Perakaran), f (Retensi } \\
\multicolumn{4}{c}{ Hara/Penyimpanan Hara) }
\end{tabular}


Dari hasil penilaian diketahui bahwa kelas kesesuaian lahan untuk tanaman pala berada pada kelas kesesuaian lahan S3 untuk semua SPT dengan faktor pembatas yang beragam. Pada SPT 22, SPT 36 dan SPT 42 dengan kelas kesesuaian lahan S3 kualitas lahan yang menjadi faktor pembatas adalah bahaya erosi (e). Pada SPT 30 kualitas lahan yang menjadi faktor pembatas adalah media perakaran (r) dan pada SPT 37 dan SPT 39 dengan kelas kesesuaian lahan S3 kualitas lahan yang menjadi faktor pembatas adalah retensi hara (f) dan bahaya erosi (e), retensi hara menyatakan penyimpanan unsur hara didalam tanah.

\section{Kesesuaian Lahan Potensial}

Untuk pertanaman pala salah satu kualitas lahan yang menjadi kendala yang ditemui secara aktual adalah tingkat bahaya erosi (e) yang disebabkan oleh kemiringan lereng. Untuk mengurangi dan mencegah tingkat bahaya erosi maka diperlukan usaha konservasi tanah. Secara garis besar, teknik pengendalian erosi dibedakan menjadi dua yaitu teknik konservasi mekanik dan vegetatif (Arsyad, 2000 dalam Idjudin, 2011). Salah satu metode konservasi mekanik yang dapat diterapkan adalah pembuatan teras. Menurut Arsyad (2010), teras berfungsi untuk mengurangi panjang lereng dan menahan air sehingga dapat mengurangi kecepatan air dan aliran permukaan serta memungkinkan penyerapan air oleh tanah. Teras yang dapat dibuat berupa teras bangku dan teras gulud. Selain pembuatan teras, pembuatan rorak juga dapat menjadi salah satu alternatif. Menurut penelitian yang dilakukan oleh Pratiwi dan Salim (2013) menunjukkan bahwa pemberian perlakuan rorak mempengaruhi besarnya aliran permukaan dan erosi.

Untuk meningkatkan $\mathrm{pH}$ dalam tanah, maka diperlukan tindakan pengapuran dalam tanah. Peningkatan $\mathrm{pH}$ tanah dengan pemberian kapur menciptakan kondisi yang lebih baik bagi aktifitas mikroba tanah dan ketersediaan unsur hara. Pengaruh langsung dari kapur adalah sebagai sumber $\mathrm{Ca}$ dan $\mathrm{Mg}$, mem-perbaiki (meningkatkan) $\mathrm{pH}$ tanah, dan meningkatkan ketersediaan hara $\mathrm{N}, \mathrm{P}$, Mo, dan hara lainnya (Burhanuddin dan Nurmansyah, 2010). Selain pengapuran usaha untuk meningkatkan kadar $\mathrm{pH}$ dalam tanah dapat dilakukan dengan penambahan bahan organik. Menurut Tufaila, Laksana dan Alam (2014), pemberian bahan organik berupa kotoran ayam dapat meningkatkan pH tanah dari 5,0 menjadi 5,8 sampai 6,4. Selain itu juga dapat meningkatkan kadar C-organik, $\mathrm{N}$ total dan $\mathrm{P}_{2} \mathrm{O}_{5}$.

Pada wilayah dengan drainase yang terhambat, perbaikan yang dapat dilakukan yaitu dengan pembuatan saluran pembuangan air (SPA) untuk membuang air berlebih. Saluran pembuangan air (SPA) Merupakan saluran terbuka yang dibuat pada permukaan tanah yang sudah diteras dengan arah tegak lurus denan arah garis kontur dengan maksud menampung sisa aliran permukaan untuk disalurkan ke tempat yang aman dari bahaya erosi dan longsornya tanah (Nursaban, 2006).

Ketinggian tempat, suhu, dan kelembaban udara merupakan kualitas lahan yang tidak dapat diubah. Ketinggian suatu tempat akan menentukan komoditas yang dapat ditanam di wilayah tersebut. Ketinggian tempat sangat erat kaitannya dengan suhu. Selain ketinggian tempat, suhu dan kelembaban udara, curah hujan merupakan salah satu kualitas lahan yang tidak dapat diubah.

\section{SIMPULAN}

Berdasarkan hasil dan pembahasan, dapat disimpulkan bahwaLahan untuk tanaman pala memiliki kelas kesesuaian 
lahan S3 (sesuai marginal) di Kecamatan Cikalongkulon, Sukaresmi dan Mande dengan faktor pembatas berupa kemiringan lereng, drainase dan kejenuhan basa;

\section{UCAPAN TERIMAKASIH}

Penelitian ini tidak akan selesai tanpa adanya bantuan dari beberapa pihak, untuk itu penulis menyampaikan terimakasih kepada BAPPEDA Kabupaten Cianjur, Balai Besar Sumberdaya Lahan Pertanian, Dinas Pertanian Kabupaten Cianjur yang telah memberikan akses data.

\section{DAFTAR PUSTAKA}

Arsyad, S. 2010. Konservasi Tanah dan Air. IPB Press. Bogor.

Badan Meteorologi, Klimatologi dan Geofisika. 2018. Buletin Informasi Iklim Provinsi Jawa Barat.

http://staklimbogor.jabar.bmkg.go .id/wpcontent/uploads/2018/09/BuletinInformasi-Iklim-Jabar-Edisi-

September-2018_webpublikasi...pdf. Diakses tanggal : 3 Juni 2019.

Badan Pusat Statistika Kabupaten Cianjur. 2018. Cianjur Dalam Angka 2018 .

https://cianjurkab.bps.go.id/public ation/2018/08/16/953437910418f b00e638f0ee/kabupaten-cianjurdalam-angka-2018.html. Diakses tanggal : 22 Januari 2019.

FAO [Food and Agriculture Organization]. 1976. A Framework For Land Evaluation. Soil Resources Development and Conservation Service Land and Water Development Devision. FAO Soil
Bulletin No. 32. Italy (IT): FAOUN.

Hardjowigeno, S. dan Widiatmaka. 2015. Evaluasi Kesesuaian Lahan dan Perencanaan Tataguna Lahan. Gadjah Mada University Press. Yogyakarta.

Haridjaja, O., D.P.T. Baskoro dan M. Setianingsih. 2013. Perbedaan nilai kadar air kapasitas lapang berdasarkan metode Alhricks, drainase bebas dan pressure plate pada berbagai tekstur tanah dan hubungannya dengan pertumbuhan bunga matahari (Helianthus annuus L). Jurnal Tanah dan Lingkungan. 15 (2): 52-59.

Idjudin, A.A. 2011. Peranan konservasi lahan dalam pengelolaan perkebunan. Jurnal Sumberdaya Lahan. 5 (2). 103-116.

Juarti. 2006. Analisis indeks kualitas tanah andisol pada berbagai penggunaan lahan di Desa Sumber Brantas Kota Batu. Jurnal Pendidikan Geografi. 21 (2): 58-71.

Nurdjannah, N. 2007. Teknologi Pengolahan Pala. Balai Besar Penelitian dan Pengembangan Pascapanen Pertanian. Bogor.

Nursaban, M. 2006. Pengendalian erosi tanah sebagai upaya melestarikan kemampuan fungsi lingkungan. Jurnal Geomedia. 4 (2): 93-116.

Palmer, A. 2005. Inceptisols. Encyclopedia of Soils in the Environment. Massey University, Palmerston North, New Zealand. Hal. 248254.

Pracaya dan P.C. Kahono. 2018. Kiat Sukses Budi Daya Kopi. PT 


\section{Maraga Borneo Tarigas. \\ Singkawang.}

Prasetyo, B.H. dan D.A. Suriadikarta. 2006.

Karakteristik, potensi dan teknologi pengelolaan tanah ultisol untuk pengembangan pertanian lahan kering di Indonesia. Jurnal Litbang Pertanian. 25 (2): 39-46.

Pratiwi dan A.G. Salim. 2013. Aplikasi teknik konservasi tanah dengan sistem rorak pada tanaman gmelina (Gmelina arborea Roxb.) di KHDTK Carita, Banten. Jurnal Penelitian Hutan dan Konservasi Alam. 10 (3): 273-282.

Setiawan, E. 2009. Kajian hubungan unsur iklim terhadap produktivitas cabe jamu (Piper retrofractum Vahl) di Kabupaten Sumenep. Agrovigor. 2 (1): 1-7.

Supriyadi, S. 2007. Kesuburan tanah di lahan kering Madura. Jurnal Embryo. 4 (2): 124-131.

Susila, K.D. 2013. Studi keharaan tanaman dan evaluasi kesuburan tanah di lahan pertanaman jeruk Desa Cenggiling, Kecamatan Kuta Selatan. Agrotrop: Journal on Agriculture Science. 3 (2): 13-20.

Tufaila, M., D.D. Laksana dan S. Alam. 2014. Aplikasi kompos kotoran ayam untuk meningkatkan hasil tanaman mentimun (Cucumis sativus L) di tanah masam. Jurnal Agroteknos. 4 (2): 120-127.

Wijanarko, A., Sudaryono dan Sutarno. 2007. Karakteristik sifat kimia dan fisik tanah alfisol di Jawa Timur dan Jawa Tengah. Jurnal Iptek Tanaman Pangan. 2 (2): 214-226.

Yulina, H., D.S. Saribun, Z. Adin dan M.H.R. $\quad 2015$. Hubungan antara kemiringan lereng dan posisi lereng dengan tekstur tanah, permeabilitas dan erodibilitas tanah pada lahan tegalan di Desa Gunungsari, Kecamatan Cikatomas Kabupaten Tasikmalaya. Jurnal Agrikultura. 26 (1): 15-22. 